\title{
Limited Knowledge of Safe Driving Practice among Drivers with Diabetes in Armenia: Association with Greater Risk of Motor Vehicle Accidents
}

\author{
Lilit Petrosyan 1*, Zhanna Ghazaryan², Greta Muradyan³, Elena Aghajanova4, Marek Brabece ${ }^{5,6}$, \\ Denisa Janíčková Žd'árská7, Katarina Halčiakova ${ }^{7}$, Jan Polák ${ }^{8}$, Brian M. Frier ${ }^{9}$, Jan Brož ${ }^{7}$
}

${ }^{1}$ N8 Policlinic, Yerevan State Medical University, Yerevan, Armenia

2"SourbAstvatsamayr" Medical Centers, Yerevan, Armenia

${ }^{3}$ Armenian-American Wellness Center, Yerevan, Armenia

${ }^{4}$ Department of Endocrinology, Yerevan State Medical University, “Muratsan” University Hospital, Yerevan, Armenia ${ }^{5}$ Institute of Computer Science, The Czech Academy of Sciences, Prague, Czech Republic

${ }^{6}$ Czech Institute of Informatics, Robotics, and Cybernetics, Czech Technical University in Prague, Prague, Czech Republic

${ }^{7}$ Department of Internal Medicine, Second Medical Faculty of Charles University, Prague, Czech Republic

${ }^{8}$ Department for the Study of Obesity and Diabetes, Third Medical Faculty of Charles University, Prague, Czech Republic

${ }^{9}$ British Heart Foundation Centre for Cardiovascular Science, The Queen's Medical Research Institute, University of Edinburgh, Edinburgh, UK

Email: *lilit.petrosyan@outlook.de

How to cite this paper: Petrosyan, L., Ghazaryan, Z., Muradyan, G., Aghajanova, E., Brabece, M., Ždárská, D.J., Halčiakova, K., Polák, J., Frier, B.M. and Brož, J. (2019) Limited Knowledge of Safe Driving Practice among Drivers with Diabetes in Armenia: Association with Greater Risk of Motor Vehicle Accidents. Journal of Diabetes Mellitus, 9, 14-23.

https://doi.org/10.4236/jdm.2019.91002

Received: December 18, 2018

Accepted: February 16, 2019

Published: February 19, 2019

Copyright $\odot 2019$ by author(s) and Scientific Research Publishing Inc. This work is licensed under the Creative Commons Attribution International License (CC BY 4.0).

http://creativecommons.org/licenses/by/4.0/ (c) (i) Open Access

\begin{abstract}
Aims: The aims of the study were to assess the degree of knowledge and adherence to the recommended safe practice for driving and the risk of road traffic accidents among people with diabetes mellitus in Armenia. Methods: A total of 628 respondents, including 200 drivers, out of 641 consecutive attendees at six diabetes clinics, participated in the survey. A modified British questionnaire on driving and diabetes was used to obtain the relevant data. The information from all 103 drivers treated with insulin and 73 taking sulfonylureas was reviewed. Results: The study revealed that of 176 insulin and sulfonylurea-treated drivers, 161 (91.5\%) had never received any advice about safe driving practices. Among the drivers, 156 (88.6\%) never measured their blood glucose before, or during driving. The survey revealed that $86(51.2 \%)$ of 168 patients had a history of at least one motor vehicle accident within the previous 5 years. The average road traffic accident rate per person/year was 0.21 . Conclusions: The study revealed a lack of knowledge among drivers with diabetes treated with insulin or sulfonylureas concerning recommended safe practices for driving. This was associated with sig-
\end{abstract}


nificant hypoglycemia while driving and an elevated rate of road traffic accidents.

\section{Keywords}

Driving, Hypoglycemia, Road Traffic Accident

\section{Introduction}

When diabetes is treated with insulin or sulfonylureas, medical fitness to drive may be influenced negatively by the development of hypoglycemia while driving, thus increase the risk of road traffic accidents [1]-[6]. This may also be influenced by diabetic eye disease that causes visual impairment. Therefore, in most western countries, diabetes is considered to be a prospective disability so necessitating routine assessment of medical fitness to drive and the imposition of restrictions on the issue of driving licences. However, in many parts of the world, particularly in under-developed countries drivers with insulin-treated diabetes are not subjected to any licensing restrictions and road safety is not a priority. A recent international survey that included 85 countries revealed a total lack of licensing restrictions in 59 (69.4\%) while medical assessment of some type was required in $29(34.5 \%)$ countries. That survey has also revealed that the absence of statutory restrictions is more common in countries with lower economic status and is associated with higher rates of road traffic fatalities [7].

Several studies have examined the relationship between driving performance and educational attainment in developed countries that apply statutory restrictions on insulin-treated drivers with diabetes and how this influences acquisition of driving licences [8] [9] [10]. More information is required in countries with a lower socio-economic status about the promotion of safe driving practices and whether these are observed by drivers with diabetes, if this situation is to be improved, particularly with respect to public safety.

Armenia is a country situated in Southwest Asia with lower economic status where at present there are no statutory restrictions on the acquisition and possession of driving licence for people with diabetes. The aims of the present study of drivers with diabetes treated with insulin or sulfonylureas were to determine the frequency of hypoglycemia while driving, to assess the degree of their knowledge about the potential risks associated with driving and estimate the rate of motor vehicle accidents.

\section{Methods and Participants}

Six specialized diabetes clinics in Yerevan invited adult patients with Type 1 (T1DM) and Type 2 diabetes (T2DM) to complete an 86-item survey questionnaire from May 2015 to April 2016, which was a supplemented and modified 
version of a British questionnaire on driving and diabetes developed by Graveling et al. [4]. The questionnaire was offered to the whole group of 641 patients, comprising all the $182 \mathrm{~T} 1 \mathrm{DM}$ patients and also to the 438 consecutively selected T2DM patients enrolled at these centers. There were 200 drivers among the 628 (97.8\%) people who finally participated in the study.

This study was approved by the Ethics Committee of Yerevan State Medical University and was performed in accordance with the Declaration of Helsinki; all participants gave written informed consent.

Questionnaires were completed by 200 drivers with diabetes, including 68 with T1DM (64 men, 6 women) and 132 with T2DM (117 men, 13 women) were analyzed. The median patient age was $53(\min 19, \max 82)$ years and the median diabetes duration was $8(\min 1, \max 31)$ years. Among 132 T2DM patients 35 were treated with insulin and 73 with a sulfonylurea derivate (SU), the remainder $(24(12 \%))$ were treated with metformin alone. Patient characteristics are shown in Table 1.

\section{Statistical Methods}

Data processing was based on standard descriptive characteristics (mean, standard deviation, relative frequency, etc.). Calculations were performed with $\mathrm{R}$, version 3.1.2 ( $\mathrm{R}$ Foundation for Statistical Computing, Vienna, Austria) [11].

\section{Results}

\subsection{Employment and Annual Mileage}

One hundred and forty-seven (75\%) participants were in full-time employment, 91 (46\%) of whom needed to drive for their jobs. There were 70 (35\%) professional drivers, with 16 being taxi drivers and 12 were lorry/truck drivers. A driving licence had been held for more than 5 years by 148 (74\%). An estimated distribution of the total distance driven annually was: $<5000$ kilometres $(\mathrm{km})=$ $30(15.0 \%)$ drivers; $5000-10,000 \mathrm{~km}=80(53.5 \%) ; 10,000-20,000 \mathrm{~km}=50$ $(25.0 \%) ;>20,000 \mathrm{~km}=40(20.0 \%)$. The average distance driven annually was $11,695 \mathrm{~km}$.

\subsection{The Frequency of Severe Hypoglycemia during Previous 12 Months}

At least one severe hypoglycemic event during the preceding 12 months was reported by 25 (26.3\%) insulin-treated drivers. 11 (11.6\%) of whom experienced two or more episodes. Among drivers with T2DM treated with a sulfonylurea, 4 (6.0\%) reported at least one severe hypoglycemic event. The mean number of severe hypoglycemic events was 0.185 in T1DM drivers, 1.51 in T2DM drivers treated with insulin and 0.187 per driver per year in T2DM drivers treated with sulfonylureas. The frequencies of severe hypoglycemia events in each treatment group are shown in Table 2. 
Table 1. Clinical characteristics of drivers with diabetes in survey.

\begin{tabular}{cccc}
\hline Variables & T1DM & $\begin{array}{c}\text { T2DM } \\
\text { with insulin }\end{array}$ & $\begin{array}{c}\text { T2DM } \\
\text { with SU }\end{array}$ \\
\hline Number of patients (M/F) & $68(64 / 4)$ & $35(31 / 4)$ & $73(67 / 6)$ \\
Age, median (Min/Max) & $35(19 / 66)$ & $58(48 / 79)$ & $56(31 / 82)$ \\
BMI, kg/m² & $26.6 \pm 7.7$ & $29.3 \pm 4.1$ & $29.5 \pm 4.4$ \\
Insulin dose, U/kg & $0.76 \pm 0.29$ & $0.56 \pm 0.3$ & 0 \\
HbAlc, \% (mmol/mol) & $8.3 \pm 1.3$ & $8.8 \pm 1.4$ & $7.9 \pm 1.2$ \\
Diabetes duration, median (Min/Max) & $9(1 / 31)$ & $142.7 \pm 11.6)$ & $(62.8 \pm 9.4)$ \\
Retinopathy, number of patients (\%) & $19(27.9)$ & $18(51.4)$ & $8(1 / 26)$ \\
$\begin{array}{c}\text { Peripheral neuropathy, number of } \\
\text { patients (\%) }\end{array}$ & $25(36.7)$ & $24(68.5)$ & $24(32.8)$ \\
$\begin{array}{c}\text { Alcohol consumption (at least one } \\
\text { alcohol unit at least once a week), } \\
\text { number of patients (\%) }\end{array}$ & $9(13.2 \%)$ & $8(22.8 \%)$ & $19(26.0 \%)$ \\
$\begin{array}{c}\text { Smoking, number of patients (\%) } \\
\text { S }\end{array}$ & $41(60.2)$ & $15(42.8)$ & $38(52.0)$ \\
\hline
\end{tabular}

Table 2. Frequency of severe hypoglycemia during the preceding 12 months in drivers with diabetes.

\begin{tabular}{cccc}
\hline $\begin{array}{c}\text { Number of episodes of } \\
\text { severe hypoglycemia }\end{array}$ & $\begin{array}{c}\text { Type 1 DM } \\
(\mathrm{n}=60)\end{array}$ & $\begin{array}{c}\text { Type 2 DM } \\
\text { (insulin-treated) } \\
(\mathrm{n}=35)\end{array}$ & $\begin{array}{c}\text { Type 2 DM } \\
\text { (SU-treated). } \\
(\mathrm{n}=67)\end{array}$ \\
\hline None & $42(70 \%)$ & $28(80 \%)$ & $63(94 \%)$ \\
1 & $10(17 \%)$ & $4(11 \%)$ & $2(3 \%)$ \\
2 & $3(5 \%)$ & $1(3 \%)$ & $1(2 \%)$ \\
3 or more & $5(8 \%)$ & $2(6 \%)$ & $1(2 \%)$ \\
\hline
\end{tabular}

$\mathrm{SU}=$ sulfonylurea.

\subsection{The Frequency of Hypoglycemia While Driving}

One or more severe hypoglycemic events during driving in the past was experienced by 7 (10.6\%) drivers with T1DM and by 1 (3.2\%) driver with insulin-treated T2DM and $3(4.5 \%)$ treated with a SU.

At least one non-severe hypoglycemic event during driving had been experienced previously by $42(64.6 \%)$ drivers with T1DM, among 18 (42.9\%) of whom reported having experienced this on 3 or more occasions. At least one non-severe hypoglycemic event during driving was reported by 11 (34.4\%) drivers with insulin-treated T2DM and by $12(17.9 \%)$ of those treated with a SU (Table 3).

\subsection{History of Road Traffic Accidents}

At least one accident with vehicular damage within the last 5 years was reported by $86(51.2 \%)$ drivers, 52 of whom were treated with insulin (29 T1DM and 23 T2DM) and 34 T2DM treated with SU; 29 (33.7\%) drivers indicated that the 
cause of their accident was diabetes-related and 8 (5 withT1DM and 3 with T2DM) considered hypoglycemia to be the cause (Figure 1 and Figure 2). The average motor vehicle accident rate was 0.21 per driver per year in the preceding 12 months.

Table 3. History of severe and non-severe hypoglycemia experienced during driving.

\begin{tabular}{|c|c|c|c|}
\hline Hypoglycemia rate & Type $1 \mathrm{DM}^{*}$ & $\begin{array}{c}\text { Type } 2 \text { DM } \\
\text { (insulin-treated) }^{\star *}\end{array}$ & $\begin{array}{c}\text { Type } 2 \text { DM } \\
\text { (SU-Treated) }^{\star * *}\end{array}$ \\
\hline \multicolumn{4}{|l|}{ Severe 1} \\
\hline None & $59 / 66(89 \%)$ & $30 / 31(97 \%)$ & $64 / 67(96 \%)$ \\
\hline$\geq 1$ & $7 / 66(11 \%)$ & $1 / 31(3 \%)$ & $3 / 67$ (5\%) \\
\hline \multirow[t]{4}{*}{ Non-severe 2 None } & $23 / 65(35 \%)$ & $21 / 32(66 \%)$ & $55 / 67(82 \%)$ \\
\hline & $11 / 65(17 \%)$ & $7 / 32(22 \%)$ & $7 / 67(11 \%)$ \\
\hline & $13 / 65(20 \%)$ & $1 / 32(3 \%)$ & $3 / 67(5 \%)$ \\
\hline & $18 / 65(28 \%)$ & $3 / 32(9 \%)$ & $2 / 67(3 \%)$ \\
\hline
\end{tabular}

$1{ }^{*}$ Number of responses $97 \%$ (66/68), ${ }^{* *}$ Number of responses $89 \%(31 / 35),{ }^{* * *}$ Number of responses $92 \%$ $(67 / 73) ; 2{ }^{\star}$ Number of responses $96 \%(65 / 68),{ }^{* *}$ Number of responses $91 \%(32 / 35)$, ${ }^{* *}$ Number of responses $92 \%(67 / 73)$.

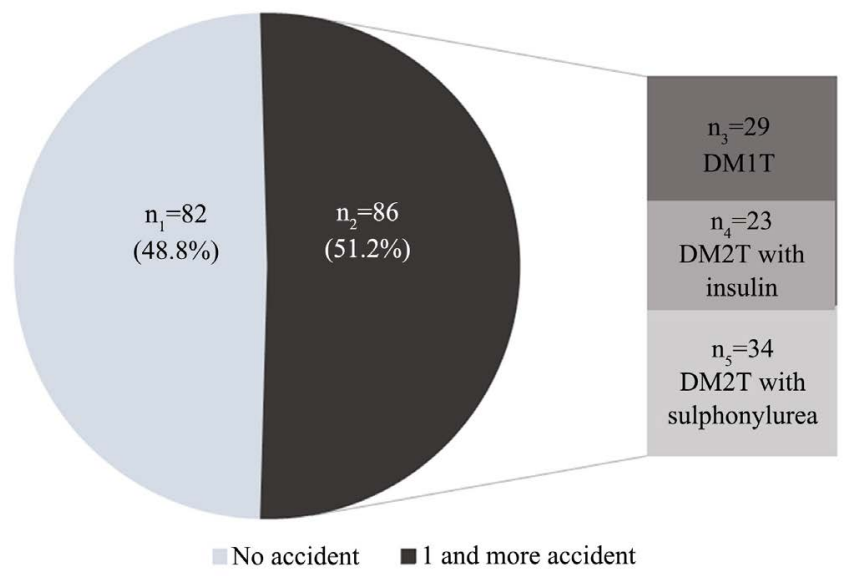

Figure 1. Proportion of patients with at least 1 motor vehicle accident during the previous 5 years.

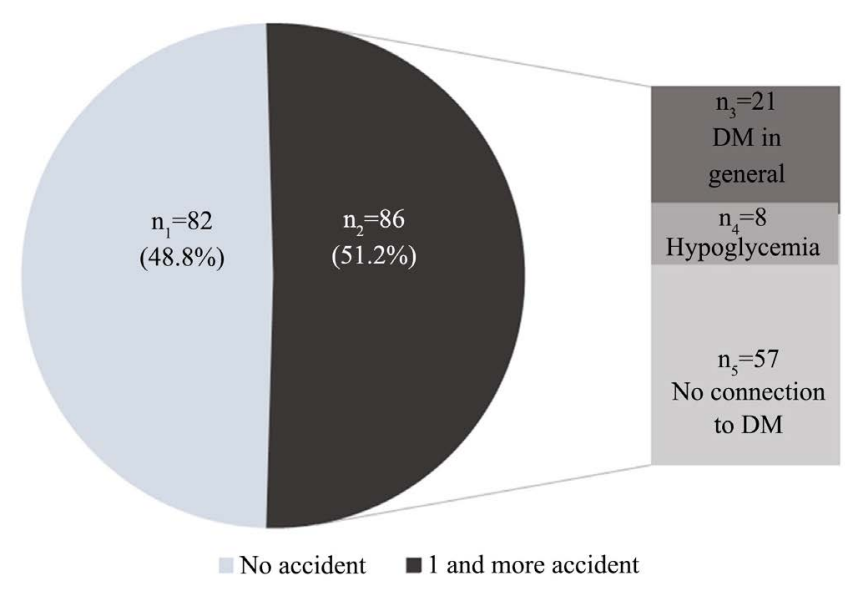

Figure 2. Patients' self-reported causes of car accidents. 


\subsection{Education of Drivers Treated with Insulin or a Sulfonylurea}

With respect to education about safe driving practice and diabetes out of 176 insulin or a SU treated patients 161 (91.5\%) had never received any advice or recommendations, and only 6 (3.4\%) had discussed this with their medical attendant. Only $32(18.2 \%)$ respondents (22 treated with insulin and 10 with SU) were aware of the fact that diabetes can potentially affect their ability to drive.

It was reported that $156(88.6 \%)$ patients never check their glucose level before and during driving, while the remaining 20 (11.4\%) respondents (18 treated with insulin, 2 with $\mathrm{SU}$ ) generally check their blood glucose only when they suspect it is too high or too low. Only $6(3.4 \%)$ patients wait at least 30 minutes before resuming driving after self-treatment of hypoglycemia while driving. The survey showed that 51 (29\%) patients (33 treated with insulin, 18 with SU) usually keep a source of glucose in their car while driving and $42(23.9 \%)$ patients (34 treated with insulin and 8 with $\mathrm{SU}$ ) reported always having a glucose meter available.

\subsection{Perceived Blood Glucose for Safe Driving}

Participants were asked what blood glucose level they considered to be the minimum for safe driving. Among T1DM patients, the value of $3.0 \mathrm{mmol} / \mathrm{l}$ was proposed by $11(17.5 \%), 20(31.7 \%)$ advocated $4.0 \mathrm{mmol} / \mathrm{l}, 30(47.6 \%)$ said 5.0 $\mathrm{mmol} / \mathrm{l}$ and $2(3.2 \%)$ gave a value of $10.0 \mathrm{mmol} / \mathrm{l}$. Among insulin-treated T2DM patients the value of $3.0 \mathrm{mmol} / \mathrm{l}$ was not indicated by anyone, $3(8.6 \%)$ chose the value of $4.0 \mathrm{mmol} / \mathrm{l}, 28(80.0 \%)$ advocated $5.0 \mathrm{mmol} / \mathrm{l}$ and $4(11.4 \%)$ suggested $10.0 \mathrm{mmol} / \mathrm{l}$. All patients who proposed the value of $5.0 \mathrm{mmol} / \mathrm{l}$ and higher were professional drivers or people needed to drive a car for their work.

Among T2DM drivers treated with a SU, the value of $3.0 \mathrm{mmol} / \mathrm{l}$ was suggested by 2 (3.0\%) respondents, 16 (23.9\%) indicated $4.0 \mathrm{mmol} / \mathrm{l}, 46$ (68.7\%) indicated $5.0 \mathrm{mmol} / \mathrm{l}$ and $3(5.5 \%)$ proposed $10.0 \mathrm{mmol} / \mathrm{l}$.

\subsection{The Frequency of Blood Glucose Monitoring}

The average frequency of blood glucose monitoring during a period of 3 months was $46.9 \pm 40.5$ measurements in drivers with T1DM, while in drivers with insulin-treated T2DM it was $45.2 \pm 39.3$ and in the drivers treated with SU it was $46.7 \pm 40.9$.

\section{Discussion}

Considerable attention is paid to driving licensing in developed countries, as in the European Union, where precise and specified statutory restrictions are imposed to ensure medical fitness to drive and maintain public safety [12]. This places responsibility on people with diabetes to adhere to the principles of safe driving. In general, many drivers in developed countries receive the support of regular diabetes review and education and have access to modern methods of treatment that are reimbursed by the health insurance companies, including the provision of a sufficient number of test strips for self-monitoring of blood glu- 
cose. Despite these advantages, many drivers with diabetes in these countries have been observed to ignore simple preventative measures for safe driving such as blood glucose testing [4].

In Armenia, possession of a driving licence is not subject to any statutory restrictions; it is issued on the basis of a medical examination carried out by a general practitioner for all the applicants. For people with diabetes, there is very little reimbursement by health insurance for purchase of essential monitoring equipment; glucose test strips are not reimbursed either for adults with insulin-treated diabetes or for people with T2DM who are treated with oral glucose-lowering medications. These exert limitations to self-management that are based on cost and lack of provision, and they undoubtedly underlie the findings of the present survey. While it would be desirable for drivers, particularly when treated with insulin, to test blood glucose more frequently in relation to driving, this is impractical for many people who cannot afford to buy glucose strips, and who do not receive any assistance from the local health care system.

The high percentage of drivers with diabetes who have experienced at least one motor vehicle accident in the last 5 years, which is more than double (51\%) the number reported for all drivers listed in the Armenian Police Register (25\%) [13], is a serious and worrying finding. Diabetes was indicated as the likely cause contributing to previous road traffic accidents by a third of drivers with T2DM who had experienced at least one road accident, of whom $27.6 \%$ indicated that hypoglycemia had been the specific cause. It was disconcerting that nearly $40 \%$ of those treated with a SU had a history of a previous road traffic accident, though this might not have been caused by hypoglycemia. Among the drivers with T1DM, 10.6\% had experienced severe hypoglycemia while driving, as had $3.2 \%$ of T2DM drivers treated with insulin and $4.5 \%$ treated with a SU. The average accident rate per person per year in the study population was 0.21 in the preceding 12 months. Unfortunately, accurate road traffic accident rates for the entire driving population in Armenia are not available. Based on an annual report in 2016 of the Armenian motor vehicle mandatory state insurance [14], the calculated accident rate per registered car was 0.12 , suggesting that the frequency of road traffic accidents is almost twice as high in drivers with diabetes treated with insulin or sulfonylureas. However, because of the limited data available in these registers, the accuracy of these estimates of greater risk associated with diabetes could not be verified.

The present findings indicate that the education on driving safety measures which are currently being provided by diabetes specialists is inadequate. $91.5 \%$ of patients indicated that they had not received any specific recommendations about driving by their doctor, and only $18 \%$ were aware of the fact that diabetes may disrupt their driving performance. Thus $89 \%$ of patients never measure their blood glucose before driving, and the others test only if they suspect that their blood glucose is either too low or too high. Only $29 \%$ of patients keep some form of carbohydrate readily available for emergency use in their vehicle if hy- 
poglycemia occurs while driving. Furthermore, only $24 \%$ always take their glucose meter with them. If hypoglycemia occurs, very few (4\%) wait at least 30 minutes after self-treatment before they recommence driving. A substantial number of drivers with T1DM (17.5\%) considered $3.0 \mathrm{mmol} / \mathrm{l}$ to be a safe level for driving. By contrast, $11.4 \%$ of this group regarded $10 \mathrm{mmol} / \mathrm{l}$ to be the safe limit, so these individuals appear to be minimising the risk of hypoglycemia while driving by allowing suboptimal glycemic control.

Present education about driving safety in Armenia is clearly insufficient. However, the practical inability to monitor blood glucose in relation to driving is a major drawback, because of the high cost to most individuals who seldom have more than 20 strips per month available for self-monitoring, despite being treated with insulin. This inability to measure blood glucose routinely when driving as is recommended, is an important factor, which may discourage physicians to provide education about the prevention of hypoglycemia while driving.

The present study has revealed that neither the knowledge of people with diabetes, nor their behaviour with regard to driving is adequate. Regular review of medical fitness to drive, particularly for people at high risk of hypoglycemia (i.e. those with type 1 diabetes and insulin-treated type 2 diabetes) is an important issue for discussion between Armenian diabetologists and the national licensing authorities. It is important that the future imposition of any national statutory restrictions are realistic in view of the current limitations of self-monitoring of blood glucose and the limited resources for education on driving safety and also to avoid having an adverse effect on the doctor-patient relationship because of the fear of revocation of the driving licence [15] [16]. The topic of diabetes and driving merits inclusion in local specialist conferences as an integral part of postgraduate education, so that it is included routinely in the education of patients in diabetes clinics. A small booklet for people with diabetes, based on recommendations for safe driving practice [17], has been prepared in Armenian and several other languages, which can be freely downloaded from http://www.diadriving.org/.

\section{Disclosure}

L.P. designed and conducted the study, performed the analysis and wrote the manuscript. Z.G., G.M., E.A., D.J.Ž. and M.K. contributed to the design and conduct of the study, and revised the manuscript. M.B. undertook the statistical analyses and analysed this work, and revised the manuscript. J.P. and B.M.F. contributed to design of the study and statistical analysis, and revised the manuscript. J.B. is the guarantor of this work and, as such, had full access to all the data in the study and takes responsibility for the integrity of the data and the accuracy of the data analysis.

\section{Funding Sources}

This article was supported by the Project for Conceptual Development of Re- 
search Organization No. 00064203 from the Ministry of Health, Czech Republic.

\section{Conflicts of Interest}

The authors declare no conflicts of interest regarding the publication of this paper.

\section{References}

[1] Harsch, I.A., Stocker, S., Radespiel-Tröger, M., et al. (2002) Traffic Hypoglycaemias and Accidents in Patients with Diabetes Mellitus Treated with Different Antidiabetic Regimens. Journal of Internal Medicine, 252, 352-360.

https://doi.org/10.1046/j.1365-2796.2002.01048.x

[2] Cox, D.J., Penberthy, J.K., Zrebiec, J., et al. (2003) Diabetes and Driving Mishaps: Frequency and Correlation from a Multinational Survey. Diabetes Care, 26, 2329-2334. https://doi.org/10.2337/diacare.26.8.2329

[3] American Diabetes Association (2012) Diabetes and Driving. Diabetes Care, 35, 81-86. https://doi.org/10.2337/dc12-s081

[4] Graveling, A.J., Warren, R.E. and Frier, B.M. (2004) Hypoglycaemia and Driving in People with Insulin-Treated Diabetes: Adherence to Recommendations for Avoidance. Diabetic Medicine, 21, 1014-1019. https://doi.org/10.1111/j.1464-5491.2004.01288.x

[5] Cox, D.J., Gonder-Frederick, L. and Clarke, W. (1993) Driving Decrements in Type I Diabetes during Moderate Hypoglycemia. Diabetes, 42, 239-243. https://doi.org/10.2337/diab.42.2.239

[6] Cox, D., Gonder-Frederick, L., Kovatchev, B., et al. (2000) Progressive Hypoglycemia's Impact on Driving Simulation Performance. Occurrence, Awareness and Correction. Diabetes Care, 23, 163-170. https://doi.org/10.2337/diacare.23.2.163

[7] Beshyah, S.A., Beshyah, A.S., Yaghi, S., et al. (2017) A Global Survey of Licensing Restrictions for Drivers with Diabetes. The British Journal of Diabetes \& Vascular Disease, 17, 3-10. https://doi.org/10.15277/bjd.2017.117

[8] Cox, D.J., Ford, D., Gonder-Frederick, L., et al. (2009) Driving Mishaps among Individuals with Type 1 Diabetes: A Prospective Study. Diabetes Care, 32, 2177-2180. https://doi.org/10.2337/dc08-1510

[9] Redelmeier, D.A., Kenshole, A.B. and Ray, J.G. (2009) Motor Vehicle Crashes in Diabetic Patients with Tight Glycemic Control: A Population-Based Case Control Analysis. PLoS Medicine, 6, e1000192. https://doi.org/10.1371/journal.pmed.1000192

[10] Brož, J., Brabec, M., Janíčková Ždárská, D., et al. (2015) Fear of Driving License Withdrawal in Insulin-Treated Diabetes Mellitus Patients Negatively Influences Their Decision to Report Severe Hypoglycemic Events to Physicians. Patient Preference and Adherence, 9, 1367-1370. https://doi.org/10.2147/PPA.S87393

[11] R Core Team (2014) R: A Language and Environment for Statistical Computing. Vienna: R Foundation for Statistical Computing. https://cran.r-project.org

[12] (2006) Commission Directive 2009/113/EC of 25 August 2009 Amending Directive 2006/126/EC of the European Parliament and of the Council on Driving Licences. Off J Eur Union, 223, 31-35.

[13] Armenian Police Registry (2017) http://www.police.am/news/view/\%D5\%B3\%D5\%BF\%D5\%BA.html

[14] Armenian Motor Vehicle Mandatory State Insurance (PAAP) (2017) Annual Re- 
port. http://www.paap.am/index.phpal=news\&pid=1\&id=300\&act=more

[15] Brož, J., Thabit, H., Ždárská, J., et al. (2016) Licensing Regulations for Diabetes and Driving-Two Sides of the Same Coin? Diabetes Research and Clinical Practice, 113, 215-216.

[16] Pedersen-Bjergaard, U., Færch, L., Allingbjerg, M.-L., et al. (2015) The Influence of New European Union Driver's License Legislation on Reporting of Severe Hypoglycemia by Patients with Type 1 Diabetes. Diabetes Care, 38, 29-33. https://doi.org/10.2337/dc14-1417

[17] Graveling, A.J. and Frier, B.M. (2015) Driving and Diabetes: Problems, Licensing Restrictions and Recommendations for Safe Driving. Clinical Diabetes and Endocrinology, 1, 8. https://doi.org/10.1186/s40842-015-0007-3 